elcome to the second issue of set for the year 2000. The response to the first issue has been exceptional. Clearly, the new format and the New Zealand content have met with approval from all sectors of the education community. The response is a clear mandate to continue in the new journal format and to deliver content that clearly reflects the Aotearoa New Zealand context.

Behaviour management, the feature topic for set 2, has been a major issue for teachers over the past twenty years. For many, the greatest problem in universal acceptance of the technology of behaviour management was its very claim to universality. For educators working within other paradigms, the notion of a universal set of behaviour principles was at best simplistic and at worst abhorrent. It seemed to legitimise elements of control and coercion that could be achieved through the manipulation of reinforcers. It was a solution-based technology. If the reinforcement was right, problems would resolve themselves.

One of my abiding memories, during training in the late 1970s, is of a very skilled gestalt therapist expressing wonder at proposed behavioural solutions, when for him the struggle was to understand the questions. For him, issues within people's lives were more than the sum of their reinforcement histories.

Since the 1980s, the impetus has swung from the technology to far more consideration of the ecology of children and young people. Although the antecedents, behaviours and consequences, as taught in the basic $\mathrm{ABCs}$, remain, behaviour management has shifted from the focus on reinforcement histories to the relationship and interaction of these with an individual's environment.

The concept of a person's environment is much wider than simply their physical or geographical context. It embraces all the elements of their internal and external existence. It is also unique to each person. The current term for this is ecology, and one of the most important elements of an individual's ecology is culture. This is conceptually interesting, because everyone has a culture, be it macro or micro, indigenous or otherwise. Culture is universal.
When culture is accepted as universal, we can come closer to understanding our own behaviour; and when we do this, we can move closer to understanding the behaviour of others. For example, consider the issue of developing peaceful schools. It is quite clear that peaceful schools require peaceful teachers. Violence cannot be stamped out. Where teachers themselves work in coercive and controlling ways, so will the students. To create peaceful schools, teachers must first examine themselves, and so come to understand their own culture.

Understanding, respect for and acceptance of another's culture are critical to the development of effective teaching and learning partnerships. This will not happen without personal reflection and self-understanding.

The common strength of the five articles on behaviour management in this issue is the way they balance practice with philosophy, technology with partnership. The technology of behaviour management is just that, a set of processes. For these to become valid, partnership must prevail. An understanding of context and culture are the foundation for partnership; without these, the predominant worldviews will continue to swamp those whose worldview is different. As one of our authors writes, "If schools are to promote every child's full participation and success in school contexts, then it is critical that the dominant culture stops marginalising minority cultures."

Behaviour management is, however, only part of the picture. The purpose of education is more than achieving compliant students and classrooms. New Zealand aims to have a worldclass, inclusive education system. This does not refer solely to the provisions made for those students who are perceived to have special learning or behavioural needs. It is about the provision of meaningful, relevant programmes for everyone. Class programmes have to be acceptable to all. Behaviour management can be central to the creation of learning environments which ensure that everyone feels they belong, and are included.

\section{Lewis Rivers}

Associate Editor

Specialist Education Services 